\title{
Eunotiaceae (Bacillariophyceae) em igarapés da Amazônia Central, Manaus e Presidente Figueiredo, Brasil
}

\author{
Fernanda FERRARI ${ }^{1}$, Letícia Knechtel PROCOPIAK, Yamile Benaion ALENCAR²; \\ Thelma Alvim Veiga LUDWIG ${ }^{3}$
}

\begin{abstract}
RESUMO
Estudos florísticos e taxonômicos envolvendo diatomáceas são escassos para a região amazônica. As publicaçōes existentes incluem registros de diatomáceas da Amazônia brasileira, do Equador, da Colômbia e do Peru e comumente mostram que Eunotia e Actinella (Eunotiaceae) são gêneros bem representados nessa região. A maioria dos igarapés amazônicos costuma apresentar potencial hidrogeniônico $(\mathrm{pH})$ ácido, característica aquática que promove o desenvolvimento de uma comunidade típica de diatomáceas, dominada por espécimes de Eunotiaceae. O objetivo deste trabalho foi providenciar um levantamento florístico das espécies de Eunotiaceae presentes em igarapés da Amazônia Central brasileira e registrar os morfotipos de algumas espécies. Amostras fitoplanctônicas e perifíticas foram coletadas em cinco igarapés na rodovia BR-174, em Manaus e Presidente Figueiredo, em setembro e outubro de 1996 e fevereiro e março de 1997. Lâminas permanentes foram preparadas de acordo com a técnica de oxidação lenta para o estudo qualitativo. Vinte e três espécies pertencentes ao gênero Eunotia e seis ao gênero Actinella foram determinadas. Chaves dicotômicas de identificação, descrição detalhada, comentários relevantes e ilustraçōes foram providenciadas para cada táxon determinado. Morfotipos foram documentados para Eunotia zygodon. Espécies raramente citadas na literatura foram registradas, tais como, Eunotia falcifera e Eunotia rostellata.
\end{abstract}

\section{PALAVRAS-CHAVE}

Eunotia, Actinella, diatomáceas, região amazônica, algas.

\section{Eunotiaceae (Bacillariophyceae) from central Amazon rivers, Manaus and Presidente Figueiredo districts, Brasil}

\begin{abstract}
Floristic and taxonomical studies about diatoms to Amazonian region are commonly well represented by Eunotia and Actinella (Eunotiaceae). The available works include diatom assemblage from Brazilian, Ecuadorian, Colombian and Peruvian Amazonia. The local streams often present acid $p H$ which provides environmental conditions to develop a very particular diatom community dominated by specimens of Eunotiaceae. Thus, the aim of this paper is to give a floristic survey of Eunotiaceae from central Amazonian rivers and to register the typical morphologic frustule variations of some species. Planktonic and periphytic samples were collected from five rivers located at the BR-174 highway, near Manaus and Presidente Figueiredo districts, during 1996 and 1997. Slides were prepared in accordance with the technique of slow oxidation for the qualitative determination. Twenty-three species of Eunotia and six of Actinella were identified. Dicotomic keys, taxonomic comments and photographic illustrations were added. Morphotypes of Eunotia zygodon were registered. Species scarcelly mentioned on diatom literature were registered, such as, Eunotia falcifera and Eunotia rostellata.
\end{abstract}

\section{KEY ZWORDS}

Eunotiaceae, Amazonia, Eunotia, Actinella, diatoms, algae.

1 Universidade Estadual do Centro-Oeste, em Guarapuava, Paraná. e-mail: fferrarii@hotmail.com

2 Pesquisadora visitante. Coordenação de Pesquisas da Amazônia-INPA. AV. André Araújo, 2936 Petrópolis. CEP: 69011-970 Caixa Postal 478. Manaus-AM

3 Departamento de Botânica da Universidade Fdederal do Paraná. e-mail: veiga@ufpr.br 


\section{INTRODUÇÃo}

Ambientes tropicais da América do Sul apresentam uma flora de diatomáceas particular se comparados com ambientes temperados da mesma região, onde as espécies são cosmopolitas ou características destas zonas climáticas. Os trabalhos florísticos e taxonômicos clássicos e recentes envolvendo diatomáceas da Amazônia revelam uma elevada biodiversidade (Sala et al., 2002 b). Kociolek et al. (2001) afirmaram que a cada sucessiva investigação sobre diatomáceas na América do Sul, é verificada uma diversidade de espécies sempre maior em relação à constatada em estudos precedentes. Entretanto, ainda há poucos estudos taxonômicos sobre diatomáceas para a Amazônia.

Entre os estudos existentes destacam-se os de Hohn (1966), Oliveira \& Steinitz-Kannan (1992) e Sala et al. (1999, 2002 a e b), que correspondem, respectivamente, a inventários de diatomáceas da Amazônia peruana, equatoriana e colombiana. Os estudos sobre algas na região amazônica brasileira iniciaramse com Gessner \& Kolbe (1934), Krasske, 1939 apud Hohn (1966) e Hustedt (1927-1966). Patrick (1940), analisando amostras de ambientes aquáticos brasileiros, incluindo a região do estado do Pará, próximo à região amazônica, ressaltou que gêneros da família Eunotiaceae, especialmente Eunotia Ehrenberg, foram os mais comuns na flora brasileira e os que apresentaram maior número de espécies. Posteriormente, Uherkovich (1976, 1981), Uherkovich \& Rai (1979) e Uherkovich \& Franken (1980) publicaram trabalhos que tratavam de vários grupos de algas, inclusive diatomáceas, obtidos do fitoplâncton e do perifíton de igarapés e rios amazônicos. Souza-Mosimann et al. (1997) identificaram 32 espécies de diatomáceas em um estudo taxonômico das diatomáceas em conteúdo estomacal de peixes (Myleus sp - pacu) coletados no lago do Prato, Amazonas, sendo Eunotia o gênero com maior número de espécies. Alencar $e t a l$. (2001), em estudo sobre a autoecologia de Simulidae (Diptera) originadas de igarapés amazônicos, determinaram 29 táxons de diatomáceas no conteúdo estomacal de larvas, dentre os quais várias espécies de Actinella Lewis e Eunotia. Espécies destes gêneros são comuns em ecossistemas aquáticos ácidos (Moro \& Furstenberger, 1997).

Cleto Filho (2003) destacou que a maioria dos igarapés amazônicos é pobre em nutrientes dissolvidos, conseqüentemente, pouco produtivos e com potencial hidrogeniônico $(\mathrm{pH})$ da água ácido. Battarbee et al. (1999) justificam o $\mathrm{pH}$ ácido da água pela baixa concentração de substâncias alcalinas nos solos das bacias de drenagem dos igarapés. Comentam que a diatomoflora dos igarapés amazônicos, pouco produtivos e ácidos, pode ser diversificada e muito característica.

Segundo De Nicola (2000), o pH está entre as variáveis mais seletivas para as diatomáceas de água doce, as quais se desenvolvem preferencialmente em estreitos intervalos de variação de $\mathrm{pH}$.
Portanto, apesar de selecionar, o $\mathrm{pH}$ ácido pode permitir o estabelecimento de uma flora rica em espécies.

O presente estudo objetivou realizar um levantamento das espécies de Eunotiaceae presentes em amostras fitoplanctônicas e perifíticas coletadas em igarapés da Amazônia Central, já que este grupo mostrou-se significativamente importante nos trabalhos anteriormente publicados para a região.

\section{MATERIAL E MÉTODOS}

A área de estudo incluiu cinco igarapés da Amazônia Central, situados na rodovia BR-174, nos municípios de Manaus e Presidente Figueiredo (AM). Alencar et al. (2001) apresenta mapa localizando os igarapés. Os corpos d'água localizam-se em áreas semi-abertas, nas seguintes coordenadas geográficas: igarapé 1 - do Ibama - $\left(02^{\circ} 39^{\prime} \mathrm{S} ; 60^{\circ} 02^{\prime} \mathrm{W}\right)$, igarapé 2 - bueiro - $\left(02^{0}\right.$ $23^{\prime} \mathrm{S}$; $\left.59^{\circ} 59^{\prime} \mathrm{S}\right)$, igarapé 3 - ZF3 - $\left(02^{\circ} 29^{\prime} \mathrm{S} ; 60^{\circ} 01^{\prime} \mathrm{W}\right)$, igarapé 4 - cemitério - $\left(02^{\circ} 02^{\prime} \mathrm{S} ; 59^{\circ} 59^{\prime} \mathrm{W}\right)$ e igarapé 5 - escada - $\left(02^{0}\right.$ $\left.02^{\prime} \mathrm{S} ; 59^{\circ} 52^{\prime} \mathrm{W}\right)$. Caracterizam-se pela pouca quantidade de sais minerais e acidez. Os valores de $\mathrm{pH}$ situam-se entre 4,4 e 5,3, de condutividade entre 9,4 e $12,6 \mu \mathrm{S} / \mathrm{cm}^{2}$ e os de temperatura variam de $20^{\circ} \mathrm{C} \mathrm{a} 25^{\circ} \mathrm{C}$. Os igarapés são do tipo terra-firme e quase todos representam escoadouros de áreas represadas que sofreram ação antrópica durante a abertura das estradas. Gramíneas predominam nas margens dos igarapés, ocorrendo também algumas espécies arbustivas. O clima da região é caracterizado como tropical chuvoso (Amw'), permanentemente quente e úmido segundo a classificação de Köppen (Alencar $e t$ al., 2001).

As amostras foram coletadas em setembro e outubro de 1996 (período menos chuvoso) e fevereiro e março de 1997 (período chuvoso), utilizando-se rede de plâncton com abertura de malha de $25 \mu \mathrm{m}$. O perifíton foi removido com o auxílio de um pincel das folhas submersas recolhidas dos igarapés. O material coletado foi preservado com solução Transeau na proporção 1:1. Lâminas permanentes foram preparadas a partir de amostras tratados para eliminação de materia orgânica de acordo com a técnica de oxidação lenta (Moreira-Filho \& Valente-Moreira, 1981). Para determinação qualitativa e registros fotográficos foi utilizado microscópio Olympus BX40, equipado com câmera fotográfica. Medidas do comprimento valvar são dadas como comprimento (compr.), e as do eixo transapical, como largura (larg.) da superfície valvar. A terminologia baseou-se em Barber \& Haworth (1981). As barras (escalas) dispostas ao lado das figuras nas pranchas equivalem a $10 \mu \mathrm{m}$.

\section{RESULTADOS E DISCUSSÃO}

Foram determinadas 29 espécies de Eunotiaceae, sendo 23 espécies de Eunotia e 6 de Actinella. Variação morfológica no contorno valvar da frústula foi documentada para Eunotia 
zygodon. Apresenta-se a seguir as espécies identificadas incluídas em chaves de identificação e acompanhadas de descrição, comentários relevantes e ilustraçôes.

\section{GÊNERO Actinella LEWIS} Lewis

Chave para identificação das espécies do gênero Actinella

1. Margens valvares onduladas. Actinella mirabilis

1.Margens valvares não onduladas

2. Ambas extremidades capitadas Actinella siolii

2. Uma ou nenhuma extremidade capitada

3.Extremidade apical truncado-arredondada Actinella peronioides

3. Extremidade apical com outras formas

4. Extremidade apical arredondada Actinella robusta

4. Extremidade apical capitada

5. Extremidade apical finalizando com um rostro um pouco deslocado para a margem dorsal da valva. Actinella brasiliensis

5. Extremidade apical finalizando com margem em ângulo agudo bem deslocado para a margem dorsal da valva Actinella curvatula

Actinella brasiliensis Grunow, in Van Heurck, Syn. Diat. Belg., pl. 35, fig. 19, 1881.

(Figs. 1 a, b)

Valvas heteropolares, levemente arqueadas; margem ventral levemente côncava; margem dorsal convexa; espinhos marginais indistintos; extremidade apical capitada, cuneada, finalizando com pequeno rostro um pouco deslocado para a margem dorsal da valva; extremidade basal atenuado-arredondada; estrias transapicais paralelas; nódulos terminais afastados das extremidades. Compr.: 38,7-74,4 $\mu \mathrm{m}$; larg.: 4,7-6,0 $\mu \mathrm{m}$; 1316 estrias em $10 \mu \mathrm{m}$.

MATERIAL EXAMINADO: BRASIL: Amazonas:

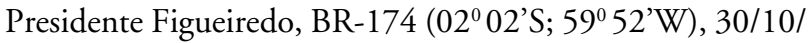
1996, Y. B. Alencar \& N. Hamada, s. n. 197.472 (INPA).

Actinella brasiliensis é uma espécie relacionada morfologicamente com Actinella lima Koc. Actinella gracile Koc. e Actinella curvatula Koc., devido à heteropolaridade das valvas $\mathrm{e}$ às extremidades cuneadas. Baseando-se em Kociolek et al. (2001), diferencia-se destas espécies por apresentar a extremidade apical cuneada, porém com angulosidade mais obtusa, menos proeminente. Nas demais espécies a extremidade é cuneada, entretanto, mais aguda e proeminente.

Actinella curvatula Kociolek in Jahn et al. Studies on diatoms, p.151-152, figs. 78-82, 104-108, 2001.
(Fig. 1 c)

Valvas heteropolares, arqueadas; margem ventral levemente côncava; margem dorsal convexa; espinhos marginais indistintos; extremidade apical capitada, cuneada, finalizando com margem em ângulo agudo bem deslocado para a margem dorsal da valva; extremidade basal atenuado-arredondada; estrias transapicais paralelas; nódulos terminais afastados das extremidades. Compr.: 64,0 - 69,0- $\mu \mathrm{m}$; larg.: 3,8-4,0- $\mu \mathrm{m}$; $15-17$ estrias em $10 \mu \mathrm{m}$.

MATERIAL EXAMINADO: BRASIL: Amazonas: Presidente Figueiredo, BR-174 (02 $02^{\circ}$ 'S; 59 $59^{\circ}$ 'W), 14/02/ 1997, Y. B. Alencar \& N. Hamada, s. n. 197.479 (INPA); idem, $\left(02^{\circ} 02^{\prime} \mathrm{S} ; 59^{\circ} 52^{\prime} \mathrm{W}\right), 30 / 10 / 1997$, Y. B. Alencar \& N. Hamada, s. n. $197.479(I N P A)$.

Actinella mirabilis (Eulenstein ex Grunow) Grunow, in Van Heurck, Syn. Diat. Bel., pl. 35, fig. 16 a-c, 1881.

(Fig. 1 e)

Valvas levemente heteropolares, arqueadas, margem ventral côncava, margem dorsal convexa, ambas onduladas; espinhos marginais pouco visíveis; extremidades capitadas, cuneadas, extremidade apical levemente mais ampla que a basal, possuindo lado dorsal reto; estrias transapicais irregulares, às vezes interrompidas, radiadas levemente em direção às extremidades; nódulos ventrais próximos das extremidades. Compr.: 122-369 $\mu \mathrm{m}$; larg.: 22-32,8 $\mu \mathrm{m}$; 9-16 estrias em $10 \mu \mathrm{m}$.

MATERIAL EXAMINADO: BRASIL: Amazonas: Presidente Figueiredo, BR-174 (02 02'S; 59 $59^{\circ} \mathrm{W}$ ), 14/02/ 1997, Y. B. Alencar \& N. Hamada, s. n. 197.479 (INPA).

Actinella peronioides Hustedt, Ber. Deutsch. Bot. Ges., 65, p. 134135, pl. 5, fig. 4, 1952

(Fig. $1 \mathrm{~g}$ )

Valvas heteropolares, retas ou levemente arqueadas; margem ventral levemente côncava; margem dorsal levemente convexa ou reta; espinhos ausentes; extremidade apical mais ampla, truncado-arredondada, extremidade basal afilado-arredondada; estrias transapicais paralelas; nódulos terminais ventrais praticamente nas extremidades valvares. Compr.: 22,1-26,8 $\mu \mathrm{m}$; larg.: 4,7 $\mu \mathrm{m}$; 16 estrias em $10 \mu \mathrm{m}$.

MATERIAL EXAMINADO: BRASIL: Amazonas: Presidente Figueiredo, BR-174 (02 $02^{\circ}$ 'S; 59 $52^{\circ}$ 'W), 30/10/ 1996, Y. B. Alencar \& N. Hamada, s. n. 197.472 (INPA).

Actinella robusta Hustedt, Ber. Deutsch. Bot. Ges., 65, p. 135, pl.5, fig. 6, 1952

(Fig. $1 \mathrm{f}$ )

Valvas heteropolares, levemente arqueadas; margem ventral levemente côncava; margem dorsal levemente convexa; espinhos inconspícuos ou ausentes; extremidade apical arredondada, mais afilada no lado dorsal da valva; extremidade basal arredondada; estrias transapicais paralelas; areolação levemente distinta; nódulos 
terminais ventrais próximos das extremidades. Compr.: 54-188 $\mu \mathrm{m}$; larg.: 3-7,1 $\mu \mathrm{m}$; 12-22 estrias em $10 \mu \mathrm{m}$.

MATERIAL EXAMINADO: BRASIL: Amazonas: Presidente Figueiredo, BR-174 (02 $02^{\circ}$ 'S; $\left.59^{\circ} 52^{\prime} \mathrm{W}\right), 30 / 10 /$ 1996, Y. B. Alencar \& N. Hamada, s. n. 197.472 (INPA).

Actinella siolii Hustedt, Internat. Ver. Gesamten Hydrobiol., v. 50, p. 392, figs. 7-10, 1965.

(Fig. 1 d)

Valvas heteropolares, fortemente arqueadas; extremidades capitadas, sendo a apical mais ampla com rostro diminuto deslocado para a margem dorsal da valva; extremidade basal menos ampla, estreitamente cuneada; margem ventral côncava; margem dorsal convexa; espinhos marginais distintos; estrias transapicais paralelas; nódulos inconspícuos. Compr.: 64-70 $\mu \mathrm{m}$; larg.: 4-4,1 $1 \mu \mathrm{m} ; 20$ estrias em $10 \mu \mathrm{m}$.

MATERIAL EXAMINADO: BRASIL: Amazonas: Presidente Figueiredo, BR-174 (02 $02^{\circ} S$; 59 $\left.59^{\circ} 52^{\prime} \mathrm{W}\right), 12 / 03$ / 1997, Y. B. Alencar \& N. Hamada, s. n. 197.466 (INPA).

\section{GÊNERO Eunotia EHRENBERG}

Chave para identificação das espécies do gênero Eunotia Ehrenberg

1. Valvas heteropolares, falciformes

Eunotia falcifera

1. Valvas isopolares, de outras formas

2. Margem dorsal com duas ou mais ondulaçōes

3. Margem dorsal contendo duas ondulaçôes

4. Extremidades fortemente cuneadas a cuneado arredondadas

Eunotia zygodon

4. Extremidades de outras formas

5. Margem ventral com intumescimento mediano Eunotia ventriosa

5. Margem sem intumescimento mediano

6. Margem ventral côncava Eunotia gibbosa

6. Margem ventral reta a ligeiramente côncava

7. Extremidades capitadas, ondulações proeminentes Eunotia schneideri

7. Extremidades rostradas, ondulaçōes suaves Eunotia sp1

3. Margem dorsal com mais de duas ondulaçōes

8. Margem dorsal com 3 ondulações

9. Margem ventral reta, ondulações suaves. ..Eunotia sp3

9. Margem ventral côncava, ondulações pronunciadas

10. Comprimento valvar inferior a $20 \mu \mathrm{m}$, extremidades curtas ..Eunotia trigibba var. abrupta

10. Comprimento valvar superior a $30 \mu \mathrm{m}$, extremidades alongadas Eunotia trigibba var. trigibba

8. Margem dorsal com mais de 3 ondulaçôes

11. Quatro ondulaçôes. Eunotia pseudoserra

11. Mais de 4 ondulaçōes. Eunotia georgii

2. Margem dorsal sem ondulações

12. Valvas com margens paralelas, retas ou arqueadas

13. Valvas praticamente retas, extremidades arredondadas pouco diferenciadas do corpo valvar Eunotia flexuosa

13. Valvas arqueadas, extremidades de formas variadas

14. Extremidades valvares destacadas do corpo valvar

15. Extremidades atenuado-arredondadas, mais estreitas do que a largura na região mediana da valva Eunotia rostellata

15. Extremidades capitadas 
16. Extremidades capitado-arredondadas, com largura semelhante à da região mediana valvar Eunotia maior

16. Extremidades capitado-truncadas, com largura maior do que à da região mediana valvar Eunotia femoriforme

14. Extremidades valvares não destacadas do corpo valvar

17. Presença de área hialina linear central, longitudinal, interrompendo as estrias Eunotia curvula

17. Ausência de linha hialina interrompendo as estrias. Eunotia sp2 12. Margens valvares não paralelas entre si

18. Extremidades capitadas Eunotia veneris

18. Extremidades nunca capitadas

19. Margem ventral côncava

20. Extremidades cuneadas, nódulos polares evidentes. Eunotia indica

20. Extremidades atenuado-arredondados, nódulos polares delicados. Eunotia bilunaris

19. Margem ventral reta

21. Extremidades largamente atenuado-arredondadas Eunotia intermedia

21. Extremidades atenuadas, estreitas, ventralmente direcionadas

22. Nódulos polares grosseiros e mais deslocados das extremidades valvares. Eunotia incisa

22. Nódulos polares mais delicados e menos deslocados das extremidades valvares......Eunotia parasiolii

Eunotia bilunaris (Ehrenberg) Souza Bull. Jard. Bot. Nat. Belg., 67: 265, 267, fig. 13. 1999.

Basiônimo: Synedra bilunaris Ehrenberg, Phys. Abh. Akad. Wiss. Berlin, p. 87, 1831 (1832).

(Figs. $1 \mathrm{j}, \mathrm{m}$ )

Valvas com margem ventral côncava a levemente côncava; margem dorsal convexa; extremidades atenuado-arredondadas; nódulos terminais delicados; estrias transapicais delicadas, paralelas no centro da valva, curvadas em direção à margem dorsal nas extremidades. Compr.: 17-49,5 $\mu \mathrm{m}$; larg.: 2,5-3,0 $\mu \mathrm{m}$; 23-24 estrias em $10 \mu \mathrm{m}$.

MATERIAL EXAMINADO: BRASIL: Amazonas: Manaus, BR-174 (02 $29^{\circ}$ 'S; $\left.60^{\circ} 01^{\prime} \mathrm{W}\right), 30 / 10 / 1996$, Y. B. Alencar \& N. Hamada, s. n. 197.493 (INPA); idem, (02 39'S; 600 02'W), 29/10/1996, Y. B. Alencar \& N. Hamada, s. n. 197.497 (INPA); idem, (02 $23^{\circ}$ 'S; 59 59'W), 13/02/1997, Y. B. Alencar \& N. Hamada, s. n. 197.478 (INPA); idem, $\left(02^{\circ} 02^{\prime} S\right.$; $\left.59^{\circ} 59^{\prime} \mathrm{W}\right)$, 14/02/1997, Y. B. Alencar \& N. Hamada, s. n. 197.479 (INPA).

A estriação delicada, os nódulos terminais diminutos e as extremidades valvares indiferenciadas do corpo valvar principal, são características de E. bilunaris. As denominaçōes E. curvata (Kütz.) Lagerst., E. lunaris (Ehr.) Grun. ou E. bilunaris (Ehr.) Mills são utilizadas na literatura. As duas primeiras espécies citadas não são válidas de acordo com o artigo 34.1 do Código Internacional de Nomenclatura Botânica, pois são sinônimos heterotípicos de E. bilunaris (Ehr.) Souza. E. bilunaris (Ehr.)
Mills também não é uma publicação válida, pois segundo Morandi (2002), Mills não aceitou o nome e o publicou como sinônimo de E. lunaris (Ehr.) Grun. Krammer \& Lange-Bertalot (1991) não fizeram referência direta ao basiônimo deste táxon, portanto, também não é uma publicação válida. Assim, Souza \& Moreira-Filho (1999), propuseram uma nova combinação, referenciando o basiônimo do táxon e o validando. De acordo com Patrick \& Reimer (1966), E. bilunaris desenvolve-se bem em lagos rasos, córregos e rios e é amplamente distribuída em águas ácidas e com baixo conteúdo mineral, podendo também ser encontrada em águas alcalinas.

Eunotia curvula Hustedt, Neue Diat. 65, p. 137, fig. 24, 1952.

(Figs. $1 \mathrm{n}$-p)

Valvas com margens paralelas; margem ventral côncava; margem dorsal convexa; extremidades arredondadas, não diferenciadas do corpo valvar; nódulos terminais nas extremidades; estrias transapicais delicadas, paralelas, interrompidas centralmente por uma área hialina linear longitudinal. Compr.: 90-168,8 $\mu \mathrm{m}$; larg.: 7-13,3 $\mu \mathrm{m}$; 13-19 estrias em $10 \mu \mathrm{m}$.

MATERIAL EXAMINADO: BRASIL: Amazonas: Manaus, BR-174 (02 $02^{\prime}$ 'S; 590 59’W), 27/09/1996, Y. B. Alencar \& N. Hamada, s. n. 197.487 (INPA).

Kociolek (2000), em estudo sobre a ultraestrutura valvar de algumas espécies de Eunotiaceae da coleção de Hustedt, incluiu 
amostras de igarapés brasileiros e apresentou ilustraçōes de Eunotia curvula, evidenciando detalhes do sistema da rafe, das aréolas e das rimopórtulas. E. curvula é semelhante à E. synedraeformis Hust. em relação ao contorno valvar e ao sistema da rafe, cuja extremidade em forma de gancho, curva-se em direção à face valvar. E. curvula, no entanto, apresenta menor eixo transapical (4,5-7 $\mu \mathrm{m}$ em E. curvula; 9-10 $\mu \mathrm{m}$ em E. synedraeformis) e contorno valvar mais arqueado do que E. synedraeformis. Esta, por sua vez, mostra extremidades mais dilatadas do que E. curvula. Os exemplares identificados na área de estudo são semelhantes às ilustraçôes de Simonsen (1987).

Formas anômalas foram comuns nas amostras analisadas. Caracterizaram-se pelo contorno valvar irregularmente ondulado e extremidades deformadas, direcionadas para uma das margens (fig. 1 p).

O limite métrico inferior do eixo apical de exemplares de $E$. curvula registrados em Hustedt (1927-1966) foram superiores $(150-500 \mu \mathrm{m})$ aos da população registrada neste trabalho, coincidindo o número de estrias em $10 \mu \mathrm{m}(21 \mathrm{em} 10 \mu \mathrm{m})$.

Eunotia falcifera Metzeltin \& Lange-Bertalot, Icon. Diat., v. 5, pl. 12, fig. 19-26, 1998.

(Fig. 2 p)

Valvas heteropolares, falciformes; margem ventral levemente côncava; margem dorsal convexa; uma das extremidades amplamente arredondada, a outra é abruptamente afiladoarredondada; nódulos terminais delicados; estrias radiadas em direção às extremidades. Compr.: 10,5-14 $\mu \mathrm{m}$; larg.: 3-5 $\mu \mathrm{m}$; 16-20 estrias em $10 \mu \mathrm{m}$.

MATERIAL EXAMINADO: BRASIL: Amazonas: Manaus, BR-174 (02002'S; 595' W), 27/09/1996, Y. B. Alencar \& N. Hamada, s. n. 197.487 (INPA).

Metzeltin \& Lange-Bertalot (1998) propuseram Eunotia falcifera baseando-se em indivíduos encontrados em amostras do rio Tapajós no Brasil. E. falcifera apresenta uma acentuada heteropolaridade e está incluída no subgênero Cultria Metzeltin \& Lange-Bertalot. A forma da extremidade e a rimopórtula basal sugerem que a espécie possui hábito epipsâmico, epizóico ou epifítico. No entanto, E. falcifera pode também ocorrer no plâncton e no metafíton, da mesma forma que outras espécies de Desmogonium, Actinella ou Eunotia. (Metzeltin \& LangeBertalot, 1998). Poucos exemplares foram registrados na área de estudo, entretanto, diante da heteropolaridade das valvas, sugerem-se estudos da ultraestrutura de E. falcifera para verificar se há caracteres suficientes para proposição de um novo gênero.

Eunotia femoriforme (Patrick) Hustedt, Nat. Albert Park, 8: 72, 1940.

Basiônimo: Desmogonium femoriforme Patrick, Not. Nat., 59:3, figs. $10,11,1940$.

(Fig. 1 q)
Valvas com margens paralelas, arqueadas; margem ventral ligeiramente côncava e a dorsal ligeiramente convexa; extremidades capitado-truncadas, alargadas; nódulos terminais ventrais, nas

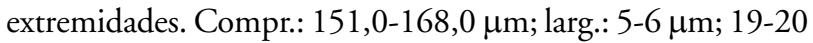
estrias em $10 \mu \mathrm{m}$.

MATERIAL EXAMINADO: BRASIL: Amazonas: Manaus, BR-174 (02 $39^{\prime}$ 'S; 6002'W), 29/10/1996, Y. B. Alencar \& N. Hamada, s. n. 197.497(INPA); idem, Presidente Figueiredo, BR-174 (02 02'S; 59 59'W), 14/02/1997, Y. B. Alencar \& N. Hamada, s. n. 197.479 (INPA).

Os exemplares observados caracterizam-se pelas extremidades capitado-truncadas e concordam com a circunscrição de Desmogonium femoriforme proposta por Patrick (1940).

Eunotia flexuosa (Brébisson in Kützing) Kützing, Spec. Algar., p. 6, 1849.

(Fig.1 r)

Basiônimo: Synedra flexuosa Brébisson in Kützing, Spec. Algar., p. 6, 1849.

Valvas com margens paralelas, retas; extremidades arredondadas pouco diferenciadas do corpo valvar; nódulos terminais ventrais, um pouco afastados das extremidades. Compr.: 133,2-381,3 $\mu \mathrm{m}$; larg.:4-8 $\mu \mathrm{m}$; 12-20 estrias em 10 $\mu \mathrm{m}$.

MATERIAL EXAMINADO: BRASIL: Amazonas: Manaus, BR-174 (020 39'S; 6002'W), 29/10/1996, Y. B. Alencar \& N. Hamada, s. n. 197.497(INPA); idem, Presidente Figueiredo, BR-174 (02 ${ }^{\circ} 02^{\prime}$ S; 595' W), 14/02/1997, Y. B. Alencar \& N. Hamada, s. n. 197.479 (INPA).

Patrick \& Reimer (1966) e Van Heurck (1896) reconhecem variedades da espécie distintas pela forma e dilatação das extremidades valvares. No entanto, Hustedt (1927-1966) não sustenta as variedades da espécie, pela ausência de outras características melhor demarcadas que diferenciem as formas individuais. As variedades de E. flexuosa também não são aceitas por Schmidt (1874-1959) ou Vanlandingham (1967-1979). Krammer \& Lange-Bertalot (1991) consideram E. flexuosa um sinônimo de E. flexuosa var. eurycephala.

Eunotia georgii Metzeltin \& Lange-Bertalot, Icon. Diat. v. 5, 61, pl 41figs. $1-7$ y pl. 42, figs 7,8. 1998.

(Fig. 2 r)

Valvas com margem ventral côncava; margem dorsal convexa, fortemente ondulada; extremidades rostrado-arredondadas, levemente direcionadas para a margem dorsal; nódulos terminais ventrais, próximos das extremidades; estrias transapicais paralelas; areolação às vezes distinta. Compr.: 48-56,8 $\mu \mathrm{m}$; larg.: 6,4-8 $\mu \mathrm{m}$; $10-13$ estrias em $10 \mu \mathrm{m}$; cerca de 2 ondulaçôes em $10 \mu \mathrm{m}$ e 9 a 11 ondulações ao longo da margem valvar. 
MATERIAL EXAMINADO: BRASIL: Amazonas: Manaus, BR-174 (02 $29^{\prime}$ 'S; 6001'W), 30/10/1996, Y. B. Alencar \& N. Hamada, s. n. 197.493 (INPA).

Segundo Metzeltin \& Lange-Bertalot (1998), Eunotia georgii caracteriza-se por apresentar indivíduos com maior número de ondulações em $100 \mu \mathrm{m}$ (16-24) e menor largura valvar (7-10 $\mu \mathrm{m})$. Diferencia-se de E. muelleri Hustedt, que apresenta extremidades mais arredondadas, menor número de ondulaçôes em $100 \mu \mathrm{m}$ e maior largura valvar.

Segundo Krammer \& Lange-Bertalot (1991), a largura valvar de $E$. serra, outra espécie semelhante, varia de 12 a 17 (20) $\mu \mathrm{m}$. A circunscrição de E. robusta Ralfs (sinônimo de E. serra), citada por Hustedt (1927-1966) e Cleve-Euler (1953), mostra largura valvar maior do que o dos indivíduos de E. georgii.

Eunotia gibbosa Grunow in Van Heurck, Syn. Diat. Belg. pl. 35, fig. 13, 1881.

\section{(Fig. $1 \mathrm{k}-\mathrm{l}$ )}

Valvas com margem ventral côncava; margem dorsal com duas ondulações; extremidades rostrado-arredondadas; nódulos terminais ventrais, distintos, próximos das extremidades; estrias paralelas no centro da valva, levemente radiadas nas extremidades. Compr.: 17,5-23,7 $\mu \mathrm{m}$; larg.: 5-5,6 $\mu \mathrm{m}$; 12-20 estrias em 10 $\mu \mathrm{m}$.

Os exemplares apresentados por Krammer \& Lange Bertalot (1991) como E.gibbosa diferem dos aqui ilustrados em relação ao contorno valvar e dimensóes (compr. 23 a $50 \mu \mathrm{m}$ e larg. 10 a 16 $\mu \mathrm{m})$. Entretanto, coincidem, em relação ao contorno valvar, com os de VanHeurck (1881). Acredita-se que os exemplares estudados no presente trabalho pertençam a $E$. gibbosa, ampliando-se os limites métricos da espécie. Sugerem-se estudos sob microscopia eletrônica de exemplares provenientes de locais diversificados, com variabilidade morfológica mais ampla, para verificar a real circunscrição da espécie. Salienta-se este fato, principalmente diante da riqueza florística de ecossistemas amazônicos, ainda pouco conhecidos.

MATERIAL EXAMINADO: BRASIL: Amazonas: Manaus, BR-174 (02 $23^{\prime} S$; 59 59'W), 13/02/1997, Y. B. Alencar \& N. Hamada, s. n. 197.478 (INPA); idem, Presidente Figueiredo, BR-174 (02 ${ }^{\circ} 02^{\prime} S$; 59 59'W), 14/02/1997, Y. B. Alencar \& N. Hamada, s. n. 197.479 (INPA).

Eunotia incisa Gregory, Quart. Journ. Microsc. Sci., v. 2, p. 96, pl. 4, fig. 4, 1854.

(Fig. 2 h)

Valvas com margem ventral reta; margem dorsal convexa; extremidades atenuadas, estreitas, ventralmente direcionadas, ligeiramente diferenciadas ou indiferenciadas do corpo valvar; nódulos terminais ventrais, distintos, mais deslocados das extremidades; estrias paralelas no centro da valva, levemente radiadas nas extremidades. Compr.: 22,9-62 $\mu \mathrm{m}$; larg.: 3,9-7,0 $\mu \mathrm{m} ; 7-12$ estrias em $10 \mu \mathrm{m}$.

MATERIAL EXAMINADO: BRASIL: Amazonas: Manaus, BR-174 (02 $39^{\prime}$ 'S; 600 02'W), 29/10/1996, Y. B. Alencar \& N. Hamada, s. n. 197.497 (INPA); idem, (022 23'S; $\left.59^{\circ} 59^{\prime} \mathrm{W}\right)$, 13/02/1997, Y. B. Alencar \& N. Hamada, s. n. 197.478 (INPA).

Jensen (1985) tratou E. incisa como sinônimo de Eunotia veneris (Kütz.) Müll. No entanto, Carter \& Flower (1988) observaram o material-tipo de E. veneris e de E. incisa diferenciando a primeira pelas extremidades valvares arredondadas e destacadas do corpo valvar e pelos nódulos terminais da rafe menos afastados das extremidades.

Eunotia indica Grunow in Rabenhorst, Beitr. Nähr. Kenntn. Verbr. Alg., v. 2, p. 5. pl. 1, fig. 7, 1865.

(Figs. $2 \mathrm{a}-\mathrm{b}$ )

Valvas com margem ventral levemente côncava; margem dorsal convexa; extremidades cuneadas; diferenciadas do corpo valvar, nódulos terminais evidentes, próximos das extremidades; estrias transapicais paralelas na região mediana da valva, levemente radiadas nas extremidades; areolação às vezes distinta. Compr.: 41,3-50,7 $\mu \mathrm{m}$; larg.: 6,7-9,2 $\mu \mathrm{m}$; 15-20 estrias em $10 \mu \mathrm{m}$.

MATERIAL EXAMINADO: BRASIL: Amazonas: Manaus, BR-174 (02 39'S; 6002'W), 29/10/1996, Y. B. Alencar \& N. Hamada, s. n. 197.497 (INPA).

Eunotia indica Grunow é morfologicamente semelhante à Eunotia pseudoindica Freng., que se caracteriza por apresentar extremidades valvares cuneadas mais prolongadas e atenuadas. E. indica possui extremidades valvares cuneadas, porém, mais arredondadas em relação à primeira espécie. E. pseudoindica, devido a morfologia das extremidades valvares (Frenguelli, 1941 ), está mais relacionada à algumas formas de $E$. zygodon (E. zygodon var. gracilis Hust.).

Eunotia indica diferencia-se de Eunotia maior (W. Sm.) Rab., também pela forma das extremidades valvares: cuneadas em $E$. indica e atenuado-arredondadas a arredondadas em $E$. maior. Além disso, E. maior apresenta contorno valvar mais linear e margem dorsal levemente convexa, enquanto em $E$. indica a margem dorsal é convexa e truncada.

Eunotia intermedia (Krasske ex Hustedt) Nörpel \& Lange-Bertalot in Pascher, Süssw.-Fl. Mitteur., v. 2, p. 3, pl. 215, fig. 143: 10-15, 1991.

(Figs. 1 h, i)

Basiônimo: Eunotia pectinalis var. minorf. intermedia Krasske ex Hustedt, Beit. Diat. Alp. Hedwigia, pl. 72, p. 92-134, 1932.

Valvas com margem ventral reta; margem dorsal convexa; extremidades atenuado-arredondadas, não diferenciadas do corpo valvar; nódulos terminais ventrais, distintos, próximos das extremidades; estrias paralelas no centro da valva, levemente 
radiadas nas extremidades. Compr.: 9,0-34 $\mu \mathrm{m}$; larg.: 1,4-3,5 $\mu \mathrm{m} ; 10-18$ estrias em $10 \mu \mathrm{m}$.

MATERIAL EXAMINADO: BRASIL: Amazonas: Manaus, BR-174 (02 $\left.{ }^{\circ} 39^{\prime} S ; 60^{\circ} 02^{\prime} \mathrm{W}\right), 29 / 10 / 1996$, Y. B. Alencar \& N. Hamada, s. n. 197.497 (INPA); idem, (02 $29^{\circ}$ 'S; 60 $01^{\circ}$ 'W), 13/02/1997, Y. B. Alencar \& N. Hamada, s. n. 197.495 (INPA).

O contorno valvar dos exemplares verificados é uma forma intermediária entre Eunotia intermedia (Krass. ex Hust.) Nörp. \& Lange-Bert. e Eunotia faba (Ehr.) Grun. A margem dorsal é menos convexa do que a de $E$. intermedia e menos arredondada do que a de $E$. faba. Táxon semelhante foi identificado como $E$. faba por Bicudo et al. (1995), com base na largura da valva e posição do nódulo. Neste trabalho, optou-se por identificar os exemplares analisados como $E$. intermedia, já que a espécie tipo de E. faba, em Van Heurck (1880-1885), apresenta contorno valvar mais globoso. Além disso, de acordo com Krammer \& Lange-Bertalot (1991), os indivíduos de E. faba possuem maiores dimensões em relação aos de E. intermedia (compr.: $14-45 \mu \mathrm{m}$; larg.: 3,5-5 $\mu \mathrm{m}$; 14-19 estrias em $10 \mu \mathrm{m}$ em E. intermedia; compr.:16-60 $\mu \mathrm{m}$; larg.: 5-9 $\mu \mathrm{m}$; 10-20 estrias em $10 \mu \mathrm{m} \mathrm{em} E$. $f a b a$ ). Alguns espécimes mostraram margem ventral levemente inflada, mas parecem ser formas teratológicas.

Eunotia maior (W. Smith) Rabenhorst, Eur. Alg. Sect. 1, p. 72, 1864.

(Fig. 2f)

Basiônimo: Himanthidium majus W. Smith, British. Diat., v. 2, p. 14, pl. 33, fig. 286, 1896.

Valvas lineares ou arqueadas; margens paralelas, margem ventral levemente côncava; margem dorsal convexa; extremidades subcapitado-arredondadas, com largura semelhante à da região mediana valvar, nódulos terminais ventrais, distintos, próximos das extremidades; estrias transapicais paralelas, levemente convergentes nas extremidades; areolação geralmente distinta. Compr.: 110,6-236 $\mu \mathrm{m}$; larg.: 13,4-20 $\mu \mathrm{m}$; 8-10 estrias em 10 $\mu \mathrm{m}$.

MATERIAL EXAMINADO: BRASIL: Amazonas: Manaus, BR-174 (02 $39^{\prime}$ 'S; 6002'W), 29/10/1996, Y. B. Alencar \& N. Hamada, s. n. 197.497 (INPA).

Patrick \& Reimer (1966) distinguem esta espécie por sua aparência linear e pelas extremidades capitado-arredondadas ligeiramente destacadas do corpo principal da valva. Eunotia maior (W. Sm.) Rab. é muito semelhante à Eunotia monodon Ehr. e, segundo o autor citado, a confusão entre essas duas espécies é devida ao fato de que Ehrenberg, em 1843, apresentou duas ilustraçōes representando dois diferentes táxons sob o mesmo epíteto específico: Eunotia monodon Ehr. Uma das figuras representava $E$. monodon, como sugerido pelo autor, a outra, tratava-se de um táxon com características que concordam com o conceito de E. maior.
Posteriormente, alguns autores (Hustedt, 1930; VanLandingham, 1967-1979) consideraram E. maior como uma variedade de E. monodon, sinonimizando-a. Krammer \& LangeBertalot (1991) trataram E. monodon var. maior (W. Sm.) Rab. como sinonímia da variedade típica (E. monodon var. monodon). Porém, a união de E. maior, E. monodon e também de Eunotia indica Grun. não é recomendável (Patrick \& Reimer, 1966), devido a diferenças morfológicas entre estes táxons.

Van Heurck (1880-1885) separou E. maior e E. monodon apresentando ilustraçóes que demonstram as diferenças entre as extremidades e a curvatura das valvas nestes táxons. Metzeltin \& Lange-Bertalot (1998), concordando com os autores já mencionados, ilustraram espécimes de $E$. maior e $E$. monodon coletados na regiáo amazônica brasileira.

Eunotia parasiolii Metzeltin \& Lange-Bertalot, Icon. Diat. v. 5, p. 72 , fig. 60 (17-30), 1998.

(Fig. 2 q)

Valvas lineares; margem ventral reta; margem dorsal convexa, extremidades atenuadas, estreitas, ventralmente direcionadas; nódulos terminais ventrais delicados deslocados das extremidades; estrias transapicais largamente espaçadas na região mediana da valva, levemente radiadas nas extremidades. Compr.: 17,5 $\mu \mathrm{m}$; larg.: $3 \mu \mathrm{m} ; 12$ estrias em $10 \mu \mathrm{m}$.

MATERIAL EXAMINADO: BRASIL: Amazonas: Manaus, BR-174 (02 $39^{\prime}$ 'S; $\left.60^{\circ} 02^{\prime} \mathrm{W}\right), 29 / 10 / 1996$, Y. B. Alencar \& N. Hamada, s. n. 197.497 (INPA).

Eunotia parasiolii Metz. \& Lange-Bert. é semelhante à Eunotia siolii Hustedt quanto às medidas de comprimento, largura e número de estrias e de aréolas em $10 \mu \mathrm{m}$. E. siolii, no entanto, apresenta margem dorsal fortemente convexa e conseqüentemente, extremidades valvares mais destacadas do corpo valvar.

Eunotia pseudoserra De Oliveira \& Steinitz-Kannan, Nova Hedwigia, v. 5. n. 3-4, p. 524, fig. 73-74, 1992.

(Fig. $2 \mathrm{k}$ )

Valvas arqueadas; margem ventral côncava; margem dorsal convexa, contendo quatro ondulaçōes pronunciadas; extremidades valvares arredondadas, distintas do corpo valvar; nódulos terminais ventrais, próximos das extremidades valvares; estrias transapicais paralelas no centro da valva, radiadas nas extremidades, areolação às vezes distinta. Compr.: 60,8-64 $\mu \mathrm{m}$; larg.: 14,2-18 $\mu \mathrm{m}$; 9-14 estrias em $10 \mu \mathrm{m}$.

MATERIAL EXAMINADO: BRASIL: Amazonas: Manaus, BR-174 (02 $\left.{ }^{\circ} 39^{\prime} S ; 60^{\circ} 02^{\prime} \mathrm{W}\right), 29 / 10 / 1996$, Y. B. Alencar \& N. Hamada, s. n. 197.497 (INPA); idem, Presidente Figueiredo, BR-174 (02 02'S; 59 59'W), 14/02/1997, Y. B. Alencar \& N. Hamada, s. n. 197.479 (INPA).

Oliveira \& Steinitz-Kannan (1992), analisando amostras de uma reserva da Amazônia equatoriana, propuseram Eunotia 
pseudoserra, com base no valor da razão comprimento/largura e no número e padrão de distribuição das estrias. Segundo estes autores, esta espécie está relacionada a Eunotia serra Ehr., diferenciando-se por apresentar menor razão comprimento/ largura, maior número de estrias e estrias mais radiadas.

Os exemplares analisados são também morfologicamente semelhantes à Eunotia robusta var. tetraodon (Ehr.) Ralfs (Schmidt, 1874-1959; Hustedt, 1927-1966; Van Heurck, 1896), Eunotia robusta var. tetraodon f. abrupta Hust. (Simonsen, 1987) e a Eunotia tetraodon Ehr. (Cleve-Euler, 1953). No entanto, estas espécies são consideradas sinônimos de E. serra (Vanlandingham, 1967-1979).

Os limites métricos dos espécimes observados concordam com os apresentados por Oliveira \& Steinitz-Kannan (1992) (compr.: 58-65 $\mu \mathrm{m}$; larg.: 15-16 $\mu \mathrm{m}$; 13-19 estrias em $10 \mu \mathrm{m}$ ), exceto para alguns indivíduos que apresentaram menor eixo transapical $(14,22 \mu \mathrm{m})$ e menor número de estrias $(9-14 \mathrm{em} 10$ $\mu \mathrm{m})$. O maior eixo transapical observado $(18 \mu \mathrm{m})$ ultrapassa os limites registrados no trabalho de descrição original da espécie. Apesar desta variação, não houve dúvidas quanto à identificação do táxon, pois o padrão radiado das estrias ao longo de toda a valva confirma os exemplares como Eunotia pseudoserra. E. pseudoserra foi registrada também em outras amostras da região amazônica brasileira por Metzeltin \& Lange-Bertalot (1998).

Eunotia rostellata Husted ex Patrick, Farlow., v. 2, n. 2, p. 163, 1945.

(Fig. $2 \mathrm{~m}$ )

Valvas arqueadas; margem ventral côncava; margem dorsal convexa, não ondulada; extremidades valvares atenuadoarredondadas, mais estreitas do que a largura na região mediana da valva, destacadas do corpo valvar, direcionadas para a margem dorsal; nódulos terminais ventrais, pouco afastados das extremidades; estrias transapicais paralelas na regiāo mediana da valva, levemente radiadas nas extremidades. Compr.: 35-35,3 $\mu \mathrm{m}$; larg.: 4-5,5 $\mu \mathrm{m}$; 19-20 estrias em $10 \mu \mathrm{m}$.

MATERIAL EXAMINADO: BRASIL: Amazonas: Manaus, BR-174 (02 29'S; 600 01'W), 13/02/1997, Y. B. Alencar \& N. Hamada, s. n. 197.495 (INPA).

Eunotia rostellata apresenta contorno valvar, comprimento e largura semelhantes aos de Eunotia valida Hust., a qual é diferenciada por apresentar menor número de estrias em $10 \mu \mathrm{m}$ (9-17) e extremidades valvares menos atenuadas (Hustedt, 1930, Krammer \& Lange-Bertalot, 1991 e Cleve-Euler, 1953). A aparência arqueada e as extremidades valvares levemente atenuadas (Patrick \& Reimer, 1966) e direcionadas para a margem dorsal são correspondentes à morfologia dos exemplares de E. rostellata apresentados por Schmidt (1874-1959) e Patrick \& Reimer (1966).
Eunotia schneideri Metzeltin \& Lange-Bertalot, Icon. Diat., v. 5, p. 77, pl. 15, fig. 1-2, 1998.

(Fig. 2 i)

Valvas lineares; margem ventral reta; margem dorsal convexa apresentando duas ondulaçôes proeminentes; extremidades capitadas, levemente direcionadas para a margem dorsal; nódulos ventrais, levemente afastados das extremidades; estrias transapicais, paralelas na região mediana da valva, radiadas em direção à margem dorsal próximo das extremidades. Compr.: 22,5-28,4 $\mu \mathrm{m}$; larg.: 4,5-11,8 $\mu \mathrm{m}$; 20-22 estrias em $10 \mu \mathrm{m}$.

MATERIAL EXAMINADO: BRASIL: Amazonas: Presidente Figueiredo, BR-174 (02 ${ }^{\circ} 02^{\prime} S$; 59 $\left.52^{\prime} \mathrm{W}\right), 30 / 10 /$ 1996, Y. B. Alencar \& N. Hamada, s. n. 197.472 (INPA); idem, Manaus, BR-174 (020 39'S; 6002'W), 29/10/1996, Y. B. Alencar \& N. Hamada, s. n. 197.497 (INPA); idem, $\left(02^{\circ} 23^{\prime} \mathrm{S}\right.$; $\left.59^{0} 59^{\prime} \mathrm{W}\right), 13 / 02 / 1997$, Y. B. Alencar \& N. Hamada, s. n. $197.478($ INPA).

Esta espécie pode ser confundida com Eunotia bidentula W. Sm., que apresenta maiores dimensões, maior número de estrias (12- $18 \mathrm{em} 10 \mu \mathrm{m})$ e ondulaçôes mais pronunciadas na margem dorsal, de acordo com Hustedt (1927-1966). E. bidentula é também considerada espécie de regiōes frias, ao contrário de $E$. schneideri, citada por Metzeltin \& Lange-Bertalot (1998) como espécie de regiōes neotropicais.

Eunotia trigibba var. abrupta Hustedt, in Schmidt et al., pl. 289, fig. 19, 1913.

(Fig. 2 o)

Valvas arqueadas; margem ventral côncava; margem dorsal convexa com ondulaçóes pronunciadas, afiladas (geralmente três); extremidades agudo-arredondadas, curtas, pouco diferenciadas do corpo valvar; nódulos terminais ventrais, distintos, nas extremidades valvares; estrias transapicais paralelas na região mediana da valva, levemente radiadas nas extremidades. Compr.: 17,3-18 $\mu \mathrm{m}$; larg.: 8,0-9,4 $\mu \mathrm{m}$; 9-10 estrias em $10 \mu \mathrm{m}$.

MATERIAL EXAMINADO: BRASIL: Amazonas: Manaus, BR-174 (020 23'S; 59 59'W), 13/02/1997, Y. B. Alencar \& N. Hamada, s. n. 197.478 (INPA).

Eunotia trigibba Hustedt var. trigibba, in Schmidt et al., pl. 286, fig. 16-18, 1874.

(Fig. 2 j)

Valvas arqueadas; margem ventral côncava; margem dorsal convexa, com ondulaçôes pronunciadas, (geralmente três ondulaçôes); extremidades alongadas, diferenciadas do corpo valvar por forte constrição da margem dorsal; nódulos terminais ventrais, distintos, nas extremidades; estrias paralelas na região mediana da valva, radiadas nas extremidades. Compr.: 34,639,5 $\mu \mathrm{m}$; Larg.: 10-11,8 $\mu \mathrm{m}$; 9-12 estrias em $10 \mu \mathrm{m}$. 
ACTA

AMAZONICA
EUNOTIACEAE (BACILLARIOPHYCEAE) EM IGARAPÉS DA AMAZÔNIA CENTRAL,

MANAUS E PRESIDENTE FIGUEIREDO, BRASIL
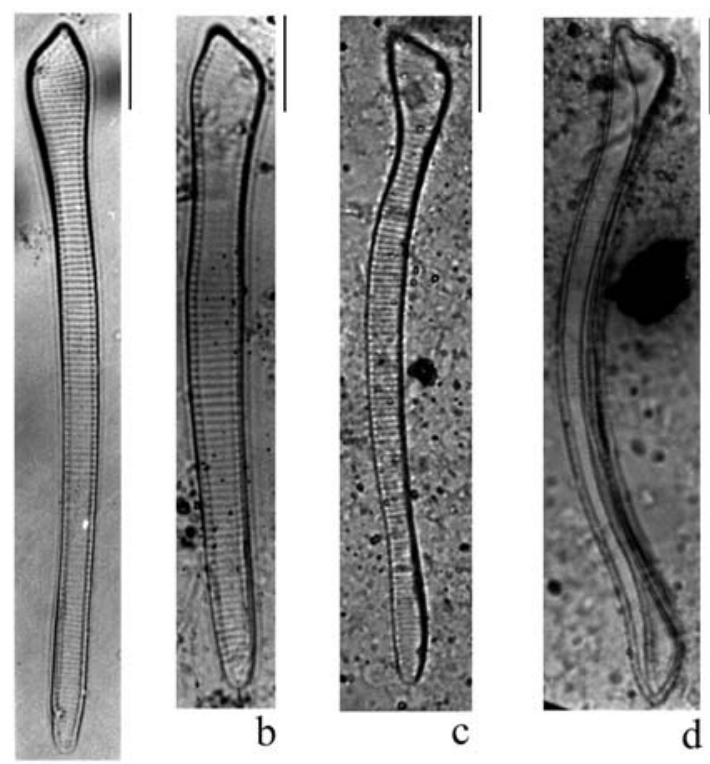

d
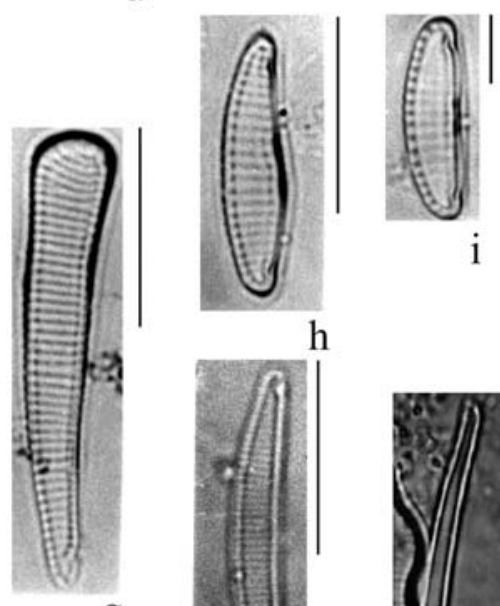

g

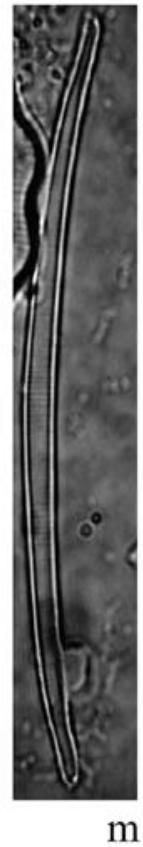

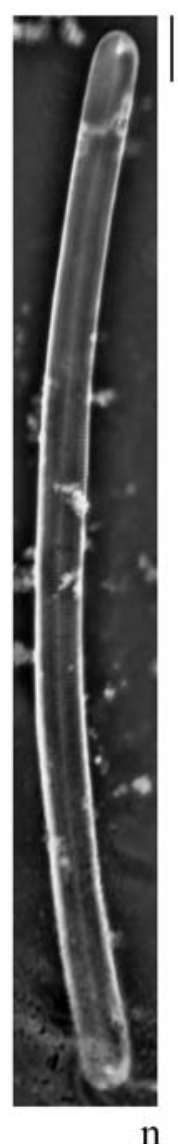
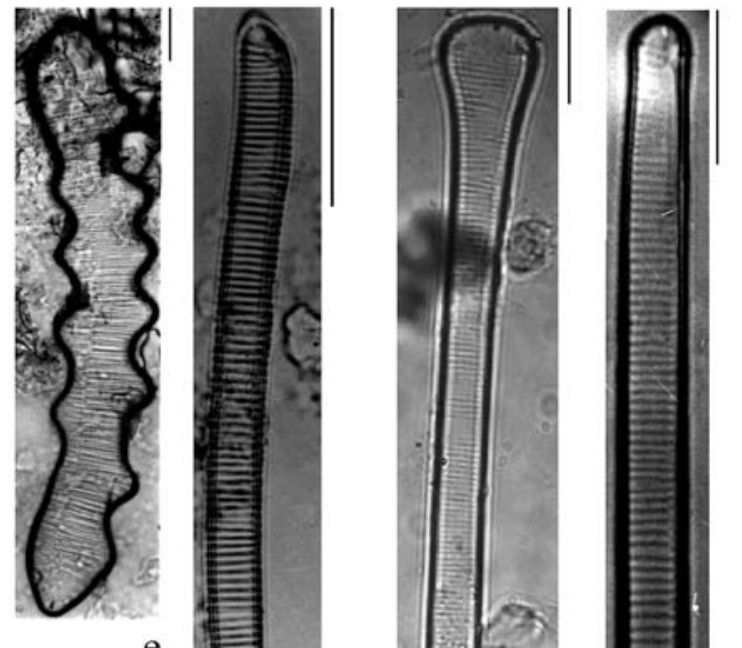

e
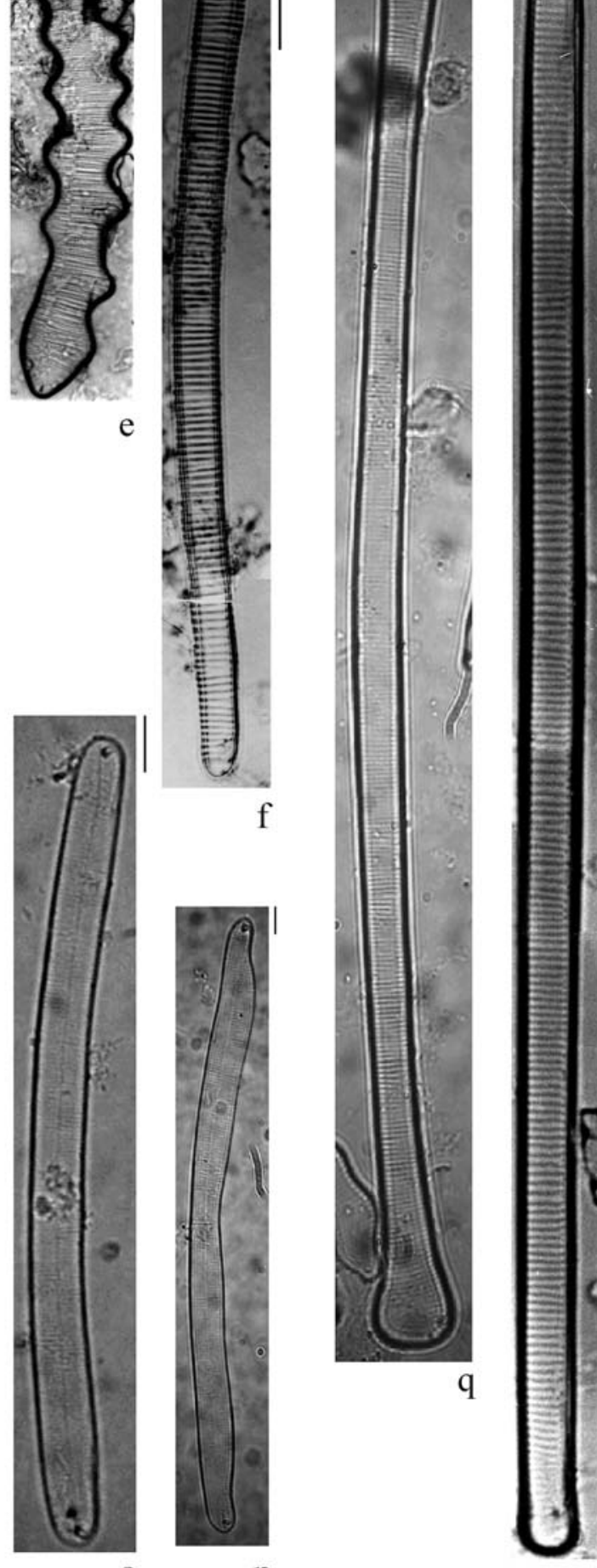

$\mathrm{p}$

Figura 1 - a, b-Actinella brasiliensis; c - Actinella curvatula; $\mathrm{d}$ - Actinella siolii; Actinella mirabilis; $\mathrm{f}$ - Actinella robusta; $\mathrm{g}$ - A. peronioides; $\mathrm{h}, \mathrm{i}$ - Eunotia intermedia; j, m - Eunotia bilunaris; k, - Eunotia gibbosa; n, o, p - Eunotia curvula; q - Eunotia femoriforme; $\mathrm{r}$ - Eunotia flexuosa. Escalas $=10 \mu \mathrm{m}$. 

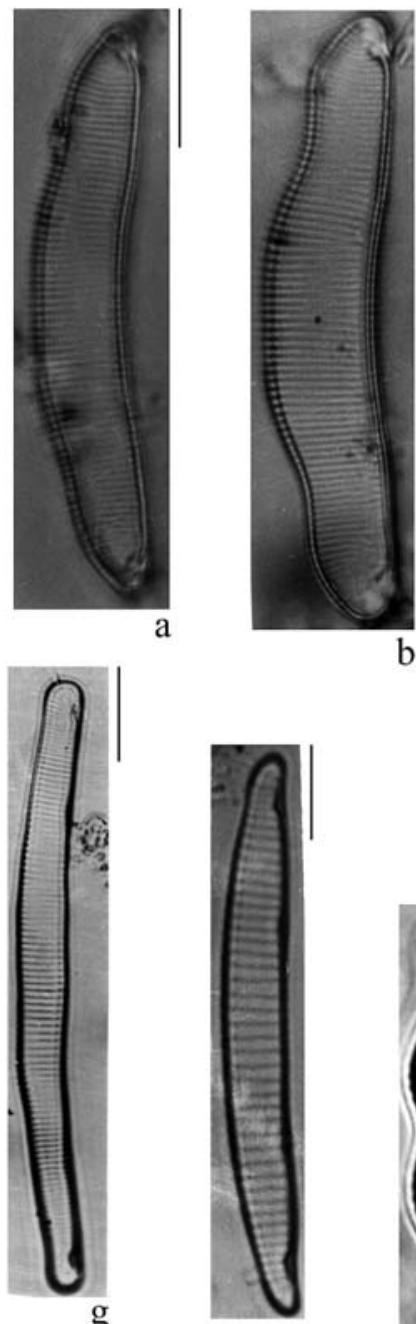

a
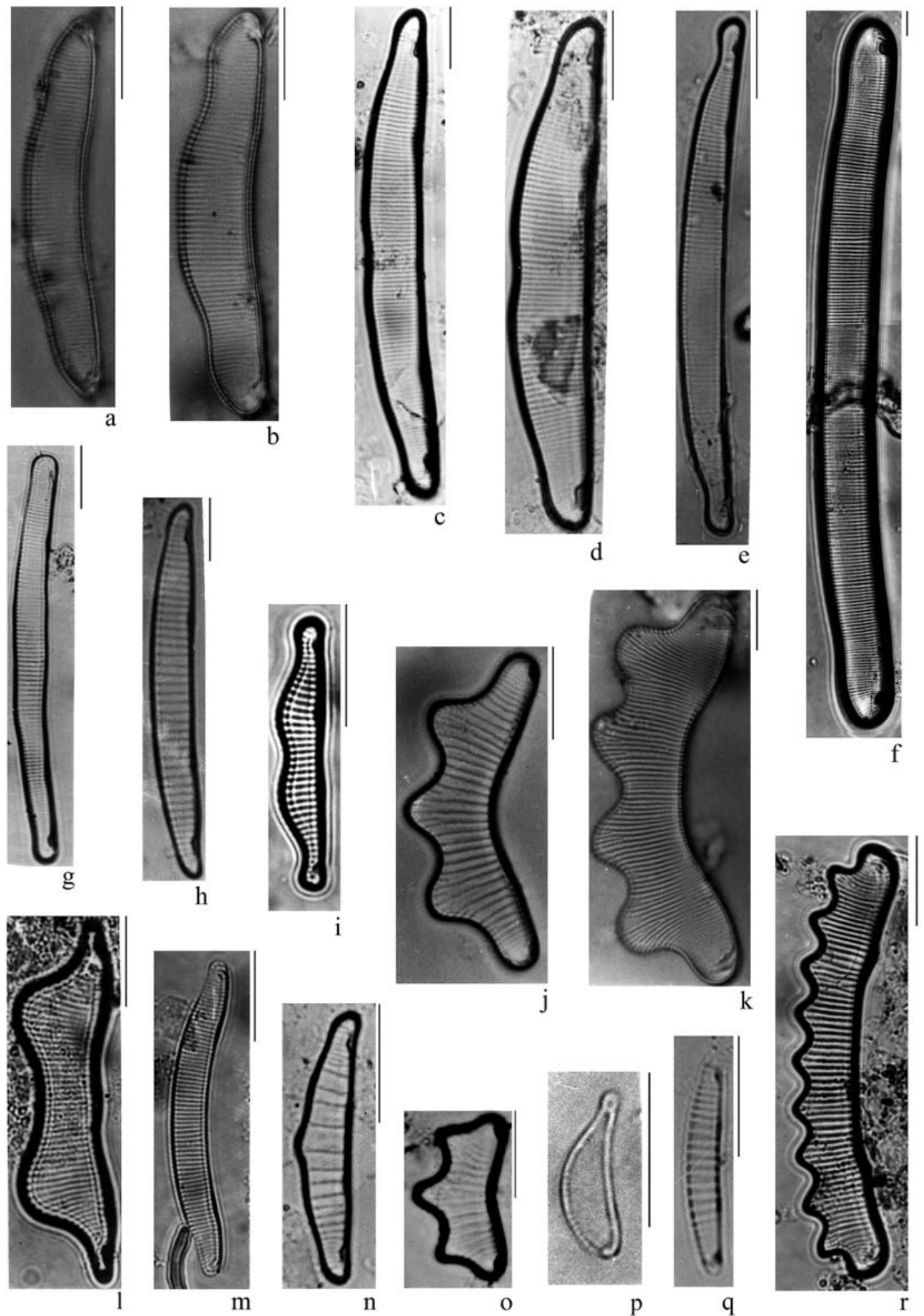

Figura 2 - Eunotia indica; c, d - Eunotia sp $1 ; \mathrm{e}$-Eunotia veneris; $\mathrm{f}-$ E. maior; $\mathrm{g}$-Eunotia sp $2 ; \mathrm{h}$-Eunotia incisa; $\mathrm{i}-$ Eunotia schneideri; $\mathrm{j}$-Eunotia trigibba var. trigibba; $\mathrm{k}$ - Eunotia pseudoserra, I - Eunotia ventriosa; $\mathrm{m}$ - Eunotia rostellata; $\mathrm{n}$ - Eunotia sp 3; 0 - Eunotia trigibba var. abrupta; $\mathrm{p}$ - Eunotia falcifera; $q$-Eunotia parasiolii; $r$ - Eunotia georgii. Escalas $=10 \mu \mathrm{m}$. 
ACTA

AMAZONICA
EUNOTIACEAE (BACILLARIOPHYCEAE) EM IGARAPÉS DA AMAZÔNIA CENTRAL,

MANAUS E PRESIDENTE FIGUEIREDO, BRASIL
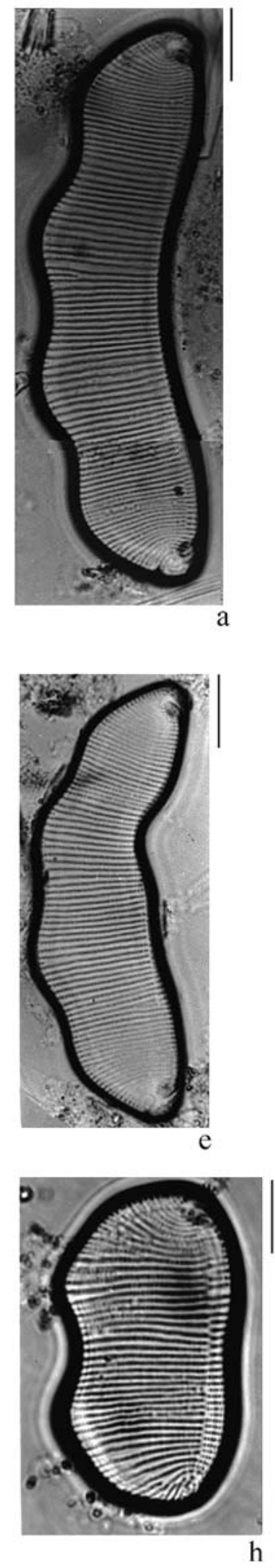
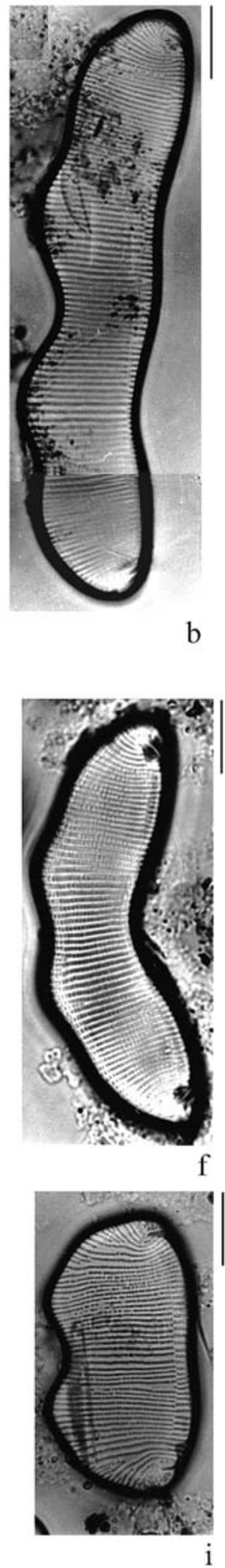
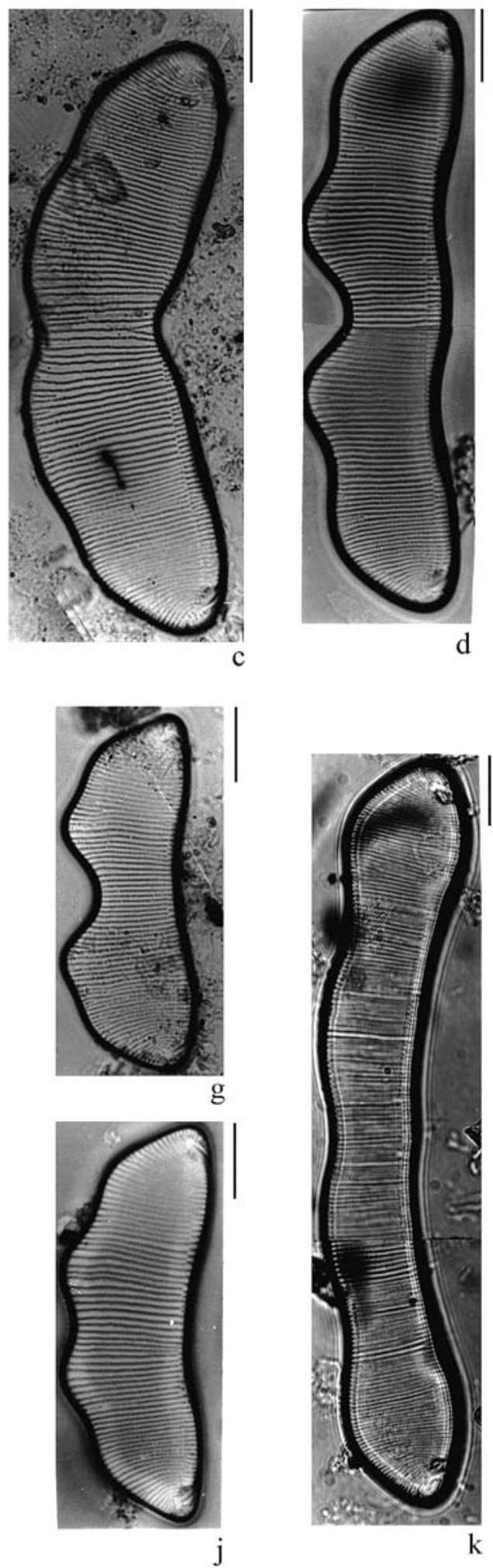

Figura 3 - a, k - Eunotia zygodon. Escalas $=10 \mu \mathrm{m}$ 
MATERIAL EXAMINADO: BRASIL: Amazonas: Manaus, BR-174 (02 $23^{\prime}$ S; 590 59'W), 13/02/1997, Y. B. Alencar \& N. Hamada, s. n. 197.478 (INPA).

Eunotia trigibba Hust. var. trigibba é muito semelhante morfologicamente à Eunotia triodon Ehr. por apresentar margem dorsal triondulada. Entretanto, E. triodon apresenta maior largura, sendo nitidamente mais robusta.

Eunotia veneris (Kützing) De Toni, Syll. Algar. Cogn., v. 2, s. 2, p. 794, 1892.

(Fig. 2 e)

Basiônimo: Himanthidium veneris Kützing, Bacill., p. 40, pl. 30, fig. 7, 1844.

Valvas levemente arqueadas; margens não paralelas, margem ventral levemente côncava; margem dorsal convexa; extremidades destacadas do corpo valvar, capitadas, levemente direcionadas para a margem dorsal; nódulos terminais ventrais, distintos, afastados das extremidades; estrias transapicais paralelas na região mediana da valva, levemente radiadas nas extremidades. Compr:: 54,5-56,6 $\mu \mathrm{m}$; larg.: 4,7-5,5 $\mu \mathrm{m}$; 12-19 estrias em $10 \mu \mathrm{m}$.

MATERIAL EXAMINADO: BRASIL: Amazonas: Manaus, BR-174 (02 ${ }^{\circ} 23^{\prime}$ S; 590 59'W), 13/02/1997, Y. B. Alencar \& N. Hamada, s. n. 197.478 (INPA); idem, Presidente Figueiredo, BR-174 (02 $02^{\circ}$ S; 59059'W), 14/02/1997, Y. B. Alencar \& N. Hamada, s. n. 197.479 (INPA).

Alguns autores (Patrick, 1958 e Patrick \& Reimer, 1966), consideraram Eunotia veneris (Kütz.) De Toni sinônimo de Eunotia incisa Greg, baseados no estudo do material tipo de Himanthidium veneris Kütz. Entretanto, Carter \& Flower (1988), Krammer \& Lange-Bertalot (1991) e Metzeltin \& Lange-Bertalot (1998) concordam que Eunotia veneris diferenciase de Eunotia incisa Greg., por esta última apresentar nódulos terminais da rafe mais afastados das extremidades, as quais são mais afiladas e não diferenciadas do corpo valvar.

Eunotia ventriosa Patrick, Not. Nat., n. 59, p. 5, fig. 6, 1940.

(Fig. $2 \mathrm{l}$ )

Valvas geralmente simétricas, lineares; margem ventral levemente côncava, com intumescimento central; margem dorsal côncava na região mediana, apresentando duas ondulaçōes; extremidades valvares fortemente afiladas; nódulos terminais conspícuos, ventrais, distintos, ligeiramente afastados das extremidades; estrias transapicais paralelas na região mediana da valva, radiadas nas extremidades. Compr.: $40-43 \mu \mathrm{m}$; larg.: 10$11 \mu \mathrm{m}$; $14-16$ estrias em $10 \mu \mathrm{m}$.

MATERIAL EXAMINADO: BRASIL: Amazonas: Manaus, BR-174 (02 $23^{\prime}$ 'S; 59 59'W), 13/02/1997, Y. B. Alencar \& N. Hamada, s. n. 197.478 (INPA).

Patrick (1940) propôs Eunotia ventriosa com base em amostras coletadas em diversos Estados brasileiros, comentando a importância do gênero Eunotia, como um dos principais gêneros de diatomáceas da flora brasileira, em termos de número de espécies. Metzeltin \& Lange-Bertalot (1998) apresentaram ilustraçōes de $E$. ventriosa Patrick (que trataram como $E$. ventricosa), diferenciando a variedade típica da var. brevis Patrick, por sua maior dimensão valvar (compr.: 33-84 $\mu \mathrm{m}$; larg.: 11,5$14 \mu \mathrm{m})$. E. ventriosa var. brevis Patrick apresenta eixos apical e transapical variando entre 8 a $30 \mu \mathrm{m}$ e 5,5 a $10 \mu \mathrm{m}$, respectivamente.

E. ventriosa é muito semelhante à Eunotia didyma Hust. ex Zimm., especialmente à forma amazonensis de E. didyma var. pseudogibbosa Torg., já que ambas possuem apenas a margem ventral triondulada. E. didyma var. pseudogibbosa f. amazonensis foi proposta por Oliveira \& Steinitz-Kannan (1992), com base apenas na triondulação da margem ventral, característica não visualizada em outras variedades e formas de $E$. didyma. A validade das variedades e formas de E. didyma foi questionada por Torgan \& Delani (1988), já que formas intermediárias entre essas variedades foram encontradas numa mesma população, estudada pelas referidas autoras. Assim, concorda-se que algumas variedades desta espécie propostas por Hustedt in Schmidt (1874-1959), assim como a forma amazonensis de Oliveira \& Steinitz-Kannan (1992), ainda não se encontram bem definidas. Segundo Metzeltin \& Lange-Bertalot (1998), provavelmente E. didyma var. pseudogibbosa f. amazonensis é sinônimo de E. ventriosa var. ventriosa.

Eunotia zygodon Ehrenberg, Abh. Akad. Wissen. Berl., p. 415, pl. 2 (1), fig. 6, 1843.

(Figs $3 \mathrm{a}-\mathrm{k}$ )

Valvas lineares ou levemente a fortemente arqueadas; margem ventral reta, côncava, abruptamente côncava ou côncava e levemente ondulada; margem dorsal convexa, com ondulações simples ou muito pronunciadas; extremidades fortemente cuneadas a cuneado-arredondadas, pouco ou muito diferenciadas do corpo valvar; nódulos terminais próximos das extremidades, ventrais; estrias transapicais paralelas, levemente radiadas nas extremidades, areolação às vezes distinta. Compr.: 39-105 $\mu$ m; larg.: 17-28 $\mu \mathrm{m}$; 9-15 estrias em $10 \mu \mathrm{m}$.

MATERIAL EXAMINADO: BRASIL: Amazonas: Manaus, BR-174 (02 $23^{\circ}$ S; 59 59'W), 13/02/1997, Y. B. Alencar \& N. Hamada, s. n. 197.478 (INPA).

Frenguelli (1933), além da variedade típica da espécie, apresenta mais três: var. compacta Hustedt, caracterizada por possuir menor comprimento valvar, ondulações dorsais muito pronunciadas e extremidades cuneadas; var. major Frenguelli, com valvas alongadas, ondulaçôes dorsais moderadamente pronunciadas e extremidades cuneadas; e a var. maxima Frenguelli, que apresenta valvas muito alongadas, extremidades atenuado-arredondadas e ondulaçôes dorsais pouco pronunciadas. Todas as variedades demonstradas por Frenguelli 
(1933) possuem margens ventrais das valvas côncavas ou levemente côncavas.

Da mesma forma, Hustedt in Schmidt (1874-1959) sugere algumas variedades e uma forma (f. genuina) para esta espécie. A forma não éválida de acordo com Vanlandingham (1967-1979). Entre as variedades, destaca-se a var. compacta, cuja ilustração difere da apresentada por Frenguelli (1933) para o mesmo táxon, no que diz respeito à concavidade da valva e forma das extremidades. Eunotia zygodon var. compacta, ilustrada em Schmidt (1874-1959), apresenta margem ventral quase reta e extremidades pouco diferenciadas do corpo valvar, enquanto o mesmo táxon, em Frenguelli (1933), apresenta margem ventral fortemente côncava e extremidades fortemente cuneadas. As variedades de Hustedt (var. emarginata, var. lata, var. gracilis e var. elongata), com exceção da variedade compacta e da variedade curta, são levemente côncavas. A variedade gracilis é tratada por Frenguelli (1933) como Eunotia indica var. gracilis Freng. Este autor comentou que no material por ele estudado, E. zygodon $\mathrm{e}$ $E$. indica encontram-se misturadas e que a última variedade mencionada está mais relacionada com Eunotia indica Grun.

E. zygodon apresentou uma população bastante variável nas amostras dos igarapés amazônicos estudadas. Foram evidenciadas desde formas bastante alongadas, retas ou levemente curvadas, com ondulações dorsais pouco ou muito pronunciadas, formas alongadas com margem ventral abruptamente côncava (lembrando a forma da letra $\mathrm{V}$ aberta), com ondulaçôes dorsais pouco pronunciadas, formas alongadas com margem ventral levemente ondulada e ondulações dorsais pronunciadas, até formas oblongas com ondulaçôes dorsais moderadamente pronunciadas. As extremidades valvares variaram desde atenuado-arredondadas a fortemente cuneadas. Assim, ficou evidente a presença de formas intermediárias entre aquelas que representam as variedades apresentadas por Frenguelli (1933) e Schmidt (1874-1959). Portanto, em função da variabilidade morfológica registrada e de algumas discordâncias entre os autores consultados, os exemplares observados foram identificados apenas em nível específico, sugerindo-se estudos que revisem as variedades propostas na literatura.

Metzeltin \& Lange-Bertalot (1998) propuseram uma nova espécie, Eunotia yanomani, com base em exemplares encontrados na Amazônia, sinonimizando $E$. zygodon e diferenciando-a desta pelas valvas com maior comprimento e pela menor largura ser superior a $10 \mu \mathrm{m}$. As dimensōes dos indivíduos analisados concordam com ambas as espécies, porém são necessários estudos mais detalhados que permitam o reconhecimento de E. yanomani.

\section{Eunotia sp. 1}

(Figs. 2 c, d)

Valvas lineares ou levemente arqueadas; margem ventral reta ou ligeiramente côncava; margem dorsal convexa, levemente retraída centralmente; extremidades rostradas, pouco diferenciadas do corpo valvar; nódulos terminais ventrais, distintos, afastados das extremidades; estrias transapicais paralelas no centro da valva, radiadas nas extremidades. Compr.: 50,6-80 $\mu \mathrm{m}$; larg.: 8,6-10 $\mu \mathrm{m} ; 15-21$ estrias em $10 \mu \mathrm{m}$.

MATERIAL EXAMINADO: BRASIL: Amazonas:

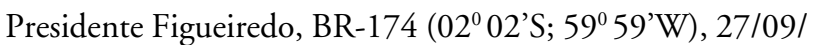
1996, Y. B. Alencar \& N. Hamada, s. n. 197.487 (INPA).

Eunotia sp. 1 assemelha-se morfologicamente à Eunotia sudetica var. bidens Hust. no que se refere ao contorno valvar e por apresentar reentrância na região mediana da margem dorsal. No entanto, de acordo com a variação métrica observada pela literatura analisada (Schmidt, 1874-1959, Hustedt, 1930 e Cleve-Euler, 1953), E. sudetica var. bidens possui maior comprimento, largura e número de estrias em $10 \mu \mathrm{m}$. Além disso, E. sudetica var. bidens apresenta extremidades valvares mais capitadas em relação aos exemplares de Eunotia sp1, que apresentaram extremidades rostradas.

\section{Eunotia sp. 2}

(Fig. $2 \mathrm{~g}$ )

Valvas geralmente simétricas; margem ventral reta, com ondulações suaves; margem dorsal levemente convexa; extremidades amplamente arredondadas, não destacadas do corpo valvar; nódulos terminais ventrais, distintos, próximos das extremidades; estrias paralelas no centro da valva, levemente radiadas nas extremidades. Compr.: 64,8-68 $\mu \mathrm{m}$; larg.: 5-7,2 $\mu \mathrm{m}$; $14-15$ estrias em $10 \mu \mathrm{m}$.

MATERIAL EXAMINADO: BRASIL: Amazonas: Manaus, BR-174 (02 $29^{\prime}$ 'S; $\left.60^{\circ} 01^{\prime} \mathrm{W}\right), 13 / 02 / 1997$, Y. B. Alencar \& N. Hamada, s. n. 197.495 (INPA).

Eunotia sp. 2 assemelha-se morfologicamente à Eunotia valida Hust. è̀ Eunotia lapponica Grun. E. valida, no entanto, apresenta margem ventral mais côncava (conseqüentemente valva mais arqueada), não ondulada e nódulos terminais mais próximos das extremidades valvares, de acordo com Simonsen (1987) e Frenguelli (1942). E. lapponica, por sua vez, diferencia-se por apresentar nódulos terminais nas extremidades, extremidades direcionadas para a margem dorsal e região mediana da valva ligeiramente mais larga do que as extremidades valvares (Krammer \& Lange-Bertalot, 1991 e Hustedt, 1930).

\section{Eunotia sp. 3}

\section{(Fig. $2 \mathrm{n}$ )}

Valvas lineares; margem ventral reta; margem dorsal convexa, contendo uma ondulação na porção central; extremidades atenuado-arredondadas; nódulos terminais ventrais, afastados das extremidades; estrias transapicais largamente espaçadas na região mediana da valva, levemente radiadas nas extremidades. Compr.: 22,5-28,1 $\mu \mathrm{m}$; larg.: 4,5-5,6 $\mu \mathrm{m}$; 8-9 estrias em 10 $\mu \mathrm{m}$. 
MATERIAL EXAMINADO: BRASIL: Amazonas: Manaus, BR-174 (02 $\left.{ }^{\circ} 39^{\prime} S ; 60^{\circ} 02^{\prime} \mathrm{W}\right), 29 / 10 / 1996, \mathrm{Y}$. B. Alencar \& N. Hamada, s. n. 197.497 (INPA).

Eunotia sp. 3 assemelha-se à Eunotia pyramidata var. monodon Krass., a qual apresenta, porém, extremidades valvares mais amplas, maior número de estrias em $10 \mu \mathrm{m}$ e nódulos terminais da rafe nas extremidades, de acordo com as ilustraçôes de Lange-Bertalot et al. (1996).

Espécies raramente citadas na literatura mundial foram registradas, tais como: Eunotia falcifera, E. rostellata, E. schneiderii e Actinella siolii.

Sugerem-se estudos adicionais para confirmar a possibilidade das espécies indeterminadas serem novidades para a ciência.

\section{BIBLIOGRAFIA CITADA}

Alencar, Y. B.; Ludwig, T. A. V.; Soares, C. C.; Hamada, N. 2001. Stomach content analyses of Simulium perflavum Roubaud 1906 (Diptera: Simuliidae) larvae from streams in central Amazonia, Brazil. Memórias do Instituto Oswaldo Cruz, 96(4): 561-576.

Barber, H. G.; Haworth, E. Y. 1981. A guide to the morphology of the diatom frustule. Freshwater Biological Association, 44, p. 1112.

Battarbee, R. W.; Charles, D. F.; Dixit, S. S.; Renberg, I. 1999. Diatoms as indicators of surface water acidity. In: Stoermer, E. F.; Smol, J. P. (Eds). The diatoms applications for the environmental and earth sciences. Cambridge University Press, Cambridge. p. 85-127.

Bicudo, D. C.; De-Lamonica-Freire, E. M. Figueiredo, D. M.; Lima, D. 1995. Ficoflórula do Pantanal de Poconé, Estado do Mato Grosso, Brasil: Centrales e Eunotiaceae (Bacillariophyceae). Hoehnea 22(1/2): 165-182.

Carter, J. R.; Flower, R. J. 1988. A new species of Eunotia, E. pirla sp. nov., from Woolmer pond, an acid pool in the southeast of England. Diatom Research, 3: 1-8.

Cleto Filho, S. E. 2003. Urbanização, poluição e biodiversidade na Amazônia. Ciência Hoje, 33(193): 72-75.

Cleve-Euler, A. 1953. Die Diatomeen von Schweden und Finnland. Kungl. Svenka Vetenskapsakademiens Handlingar. 4(5): 1-225.

De Nicola, D. M. 2000. A review of diatoms found in highly acidic environments. Hydrobiologia, 433: 111-112.

Frenguelli, J. 1933. Diatomeas de la region de los esteros del Yberá. Anales del Museo Nacional de Historia Natural, 37: 365-476.

Frenguelli, J. 1941. Diatomeas del rio de La Plata. Revista del Museo de La Plata, 3(15): 213-334.

Frenguelli, J. 1942. Diatomeas del Neuquen (Patagonia). Revista del Museo de La Plata, Sec. Botanica, 20: 73-219.

Gessner, F.; Kolbe, R. W. 1934. Ein Beitrag zur Kenntnis der Algenflora des unteren Amazonas. Berichte Deutsch. Bot. Ges., 52(3): 162

Hohn, M. H. 1966. The Catherwood Foundation Peruvian-Amazon Expedition XVII - Bacillariophyta. Monographs of the Academy of Natural Sciences of Philadelphia. 14: 459-495.
Hustedt, F. 1930. Bacillariophyta (Diatomeae). In Pascher, A. (Ed.) Die Süsswasser-flora Mitteleuropas, Vol. 10, G. Fischer, Jena, 466pp.

Hustedt, F. 1927-1966. Die kieselalgen. In: Rabenhorst (Ed.), L. Kryptogamen-Flora. Vol. 7(1-3). Akademische Verlagsgesellschaft, Leipzig. 2581pp.

Jensen, N. G. 1985. Hustedt's "Die Kieselalgen”: The Pennate Diatoms. Vol. 2. Koeltz Scientific Books, Koenigstein. 918pp.

Krammer, K.; Lange-Bertalot, H. 1991. Bacillariophyceae: Centrales, Fragilariaceae, Eunotiaceae. In: Etil, H.; Gerloff, I.; Heynig, H.; Mollenhauer, D. (Eds). Süsswasser flora von Mitteleuropa. Vol. 2(3). G. Fischer, Jenna. p. 1-576.

Kociolek, J. P. 2000. Valve ultrastructure of some Eunotiaceae (Bacillariophyceae), with comments on the evolution of the raphe system. Proceedings of the California Academy of Sciences, 52 (2): $11-21$

Kociolek, J. P.; Lyon, D.; Spaulding, S. 2001. Revision of the American species of Actinella. In: Jahn, R.; Kociolek, J. P.; Witkowski, A.; Còmpere, P. (Eds). Lange-Bertalot-Festschrifts. Studies on Diatoms. A. R. G. Gartner Verlag K.G. p. 131-135.

Lange-Bertalot, H.; Külbs, K.; Lauser, T.; Nörpel-Schemp, M. Willmann, M. 1996. Diatom Taxa introduced by Georg Krasske Documentation and Revision. Iconographia Diatomologica, 3: 1 358.

Metzeltin, D.; Lange-Bertalot, H. 1998. Tropical Diatoms of South America. Iconographia Diatomologica, 5: 1-695.

Morandi, L. L. 2002. Eunotiales (Bacillariophycae) de águas continentais do estado de São Paulo: levantamento florístico. Master's Thesis, Universidade de São Paulo, Ribeirão Preto, São Paulo. 156p.

Moreira-Filho, H.; Valente-Moreira, I. M. 1981. Avaliação taxonômica e ecológica das diatomáceas (Bacillariophyceae) epífitas em algas pluricelulares obtidas nos litorais dos estados do Paraná, Santa Catarina e São Paulo. Boletim do Museu Botânico Municipal, 47: 1-17.

Moro, R. S.; Furstenberger, C. B. 1997. Catálogo dos principais parâmetros ecológicos de diatomáceas não-marinhas. Editora UEPG, Ponta Grossa, PR, BR. 282pp.

Oliveira, P. E.; Steinitz-Kannan, M. 1992. The diatom flora (Bacillariophyceae) of the Cuyabeno Faunistic Reserve, Equadorian Amazonia. Nova Hedwigia, 54(3-4): 515-552.

Patrick, R. 1940. Diatoms of northeastern Brazil. Part I. Coscinodiscaceae, Fragilariaceae and Eunotiaceae. Proceedings of Academy of Natural Sciences of Philadelphia, 92: 191-226.

Patrick, R. 1958. Some nomenclatural problems and a new species and a new variety in the genus Eunotia (Bacillariophyceae). Notulae Nature, 312: 1-15.

Patrick, R.; Reimer, C. W. 1966. The diatoms of United States. Vol. 1. Academy of Natural Sciences, Philadelphia. 688pp.

Sala, S. E.; Duque, S. R.; Nuñez-Avellaneda, M.; Lamaro, A. A. 1999. Nuevos registros de Diatomeas (Bacillariophyceae) de la Amazonia Colombiana. Caldasia, 21(1): 26-37.

Sala, S. E.; Duque, S. R.; Nuñez-Avellaneda, M.; Lamaro, A. A. 2002a. Diatoms from Colombian Amazon. Cryptogamie Algologie. 23(1): 75-99. 
Sala, S. E.; Duque, S. R.; Nuñez-Avellaneda, M.; Lamaro, A. A. 2002b. Diatoms from the Colombian Amazon: some species of the genus Eunotia (Bacillariophyceae). Acta Amazonica, 33(4): 589-603.

Schmidt, A. 1874-1959. Atlas der Diatomaceen-Kunde. Leipzig, O. R., Reisland. II.

Simonsen, R. 1987. Atlas and catalogue of the diatom types of Friedrich Hustedt. Vol. 1, 2, 3. In: Gebrüder Nortraeger Versbuchhandlung, J. Cramer, Stuttgart. p. 1-525.

Souza-Mosimann, R. M.; Tavares, A. S.; Freitas, V. P. 1997. Contribuição ao conhecimento da diatomoflórula do conteúdo estomacal de algumas espécies de peixes da Amazônia. I. Myleus sp. (pacú) do lago do Prato, AM, Brasil. Acta Amazonica, 27(1): 9-26.

Souza, M. G. M.; Moreira-Filho, H. 1999. Diatoms (Bacillariophyceae) of two aquatic macrophyte banks from Lagoa Bonita, Distrito Federal, Brazil, I: Thalassiosiraceae and Eunotiaceae. Bulletin Jard. Bot. Nat. Bel./ Bulletin Natural Planteniun Belg., 67: 259-278.

Torgan, L. C.; Delani, O. M. 1988. Estudo taxonômico de diatomáceas (Bacillariophyceae) do Complexo Banhado Grande,
Rio grande do Sul, Brasil: representantes do gênero Eunotia Ehr. Iheringia, Série Botânica, 38: 81-107.

Uherkovich, G. 1976. Algen aus den Flüssen Rio Negro und Tapajós. Amazoniana, 5: 475-515.

Uherkovich, G. 1981. Algen aus einigen Gewaessem Amazoniens. Amazoniana, 7(2): 191-219.

Uherkovich, G.; Franken, M. 1980. Aufwuchsalgen aus zentral amazonischen Regenwaldbächen. Amazoniana, 7(1): 49-79.

Uherkovich, G.; Rai, H. 1979. Algen aus dem Rio Negro und seinen Nebenflüssen. Amazoniana, 6(4): 611-638.

Van Heurck, H. 1880-1885. Synopsis des diatomées de Belgique. L'Auteur Anver. 235pp.

Van Heurck, H. 1896. A Treatise on the Diatomaceae. William Wesley \& Son, London. 558pp.

VanLandingham, S. L. 1967-1979. Catalogue of the fossil and recent genera and species of diatoms and their synonym. J. Cramer, Sttutgart. Vol. 1-8. 4654pp.

Recebido em 06/10/2006

Aceito em 02/02/2007 